Rabaska

Revue d'ethnologie de l'Amérique française

\title{
La Nouvelle Encyclopédie des antiquités du Québec
}

Volume 6, 2008

URI : https://id.erudit.org/iderudit/019983ar

DOI : https://doi.org/10.7202/019983ar

Aller au sommaire du numéro

Éditeur(s)

Société québécoise d'ethnologie

ISSN

1703-7433 (imprimé)

1916-7350 (numérique)

Découvrir la revue

Citer ce document

(2008). La Nouvelle Encyclopédie des antiquités du Québec. Rabaska, 6, 93-93. https://doi.org/10.7202/019983ar d'utilisation que vous pouvez consulter en ligne.

https://apropos.erudit.org/fr/usagers/politique-dutilisation/ 


\section{Place publique}

Points de vue / livre

\section{La Nouvelle Encyclopédie des antiquités du Québec}

La réécriture d'un classique du domaine du patrimoine matériel, qui couronne en quelque sorte une facette marquante de la carrière de Michel Lessard, devait retenir l'attention de notre rubrique « point de vue». Plus de trentecinq ans après la parution de L'Encyclopédie des antiquités du Québec, aux Éditions de l'Homme en 1971, voit le jour La Nouvelle Encyclopédie des antiquités du Québec, un ouvrage entièrement refondu, augmenté et enrichi d'une remarquable illustration. Trois spécialistes de la culture matérielle donnent leur point de vue sur ce livre marquant à plus d'un titre: Yves Bergeron, ethnologue qui succède à Michel Lessard à l'Université du Québec à Montréal, Gerald Pocius, de l'Université Memorial à Saint-Jean, TerreNeuve, et Martine Houze, expert en art populaire français et objets de curiosité.

Michel Lessard, La Nouvelle Encyclopédie des antiquités du Québec, Montréal, les Éditions de l'Homme, 2007, 1103 p.

ISBN 9782761919333.

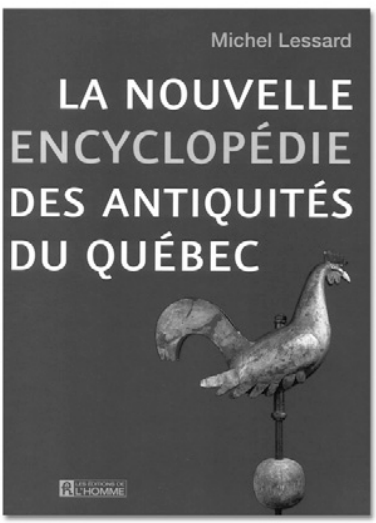

